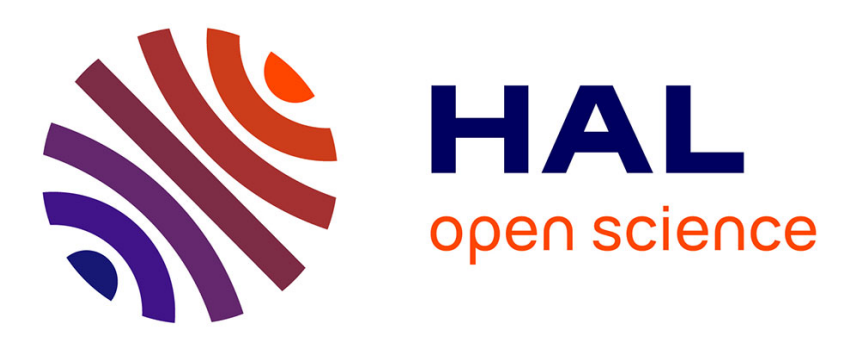

\title{
Performing pull-ups with small climbing holds influences grip and biomechanical arm action
}

\author{
Laurent Vigouroux, Marine Devise, Théo Cartier, Clément Aubert, Eric
}

Berton

\section{- To cite this version:}

Laurent Vigouroux, Marine Devise, Théo Cartier, Clément Aubert, Eric Berton. Performing pull-ups with small climbing holds influences grip and biomechanical arm action. Journal of Sports Sciences, 2018, pp.886-894. 10.1080/02640414.2018.1532546 . hal-02530195

\section{HAL Id: hal-02530195 \\ https://hal-amu.archives-ouvertes.fr/hal-02530195}

Submitted on 3 Apr 2020

HAL is a multi-disciplinary open access archive for the deposit and dissemination of scientific research documents, whether they are published or not. The documents may come from teaching and research institutions in France or abroad, or from public or private research centers.
L'archive ouverte pluridisciplinaire HAL, est destinée au dépôt et à la diffusion de documents scientifiques de niveau recherche, publiés ou non, émanant des établissements d'enseignement et de recherche français ou étrangers, des laboratoires publics ou privés. 


\section{Performing pull-ups with small climbing holds influences grip and biomechanical arm action}

\section{Laurent Vigouroux, Marine Devise, Théo Cartier, Clément Aubert \& Eric Berton}

To cite this article: Laurent Vigouroux, Marine Devise, Théo Cartier, Clément Aubert \& Eric Berton (2018): Performing pull-ups with small climbing holds influences grip and biomechanical arm action, Journal of Sports Sciences, DOI: 10.1080/02640414.2018.1532546

To link to this article: https://doi.org/10.1080/02640414.2018.1532546

\section{Published online: 16 Oct 2018.}

Submit your article to this journal ¿

View Crossmark data ¿ 


\title{
Performing pull-ups with small climbing holds influences grip and biomechanical arm action
}

\author{
Laurent Vigourouxa ${ }^{\mathrm{a}}$,Marine Devise ${ }^{\mathrm{a}}$, Théo Cartier ${ }^{\mathrm{a}}$, Clément Aubert ${ }^{\mathrm{b}}$ and Eric Berton ${ }^{\mathrm{a}}$ \\ aCNRS, ISM UMR 7287, Aix-Marseille Université, Marseille, France; bSATT sud-est, Aix-Marseille Université, Marseille, France
}

\begin{abstract}
Pull-ups are often used by sport-climbers and other athletes to train their arm and back muscle capabilities. Sport-climbers use different types of holds to reinforce finger strength concomitantly. However, the effect of grip types on pull-up performance had not previously been investigated. A vertical force platform sensor measured the force exerted by climbers when performing pull-ups under six different grip conditions (gym-bar, large climbing hold, and four small climbing holds: $22 \mathrm{~mm}, 18 \mathrm{~mm}$, $14 \mathrm{~mm}$, and $10 \mathrm{~mm})$. The electromyography of finger flexors and extensor muscles were recorded simultaneously. The maximal arm power and summed mechanical work were computed. The results revealed that the number of pull-ups, maximal power, and summed mechanical work decreased significantly with the size of the climbing hold used, even if no differences were found between a large climbing hold and a gym-bar. Electromyography of the forearm muscles revealed that the use of a climbing hold generated finger flexor fatigue and that the level of cocontraction was impacted by the different segment coordination strategies generated during the pull-ups. These findings are likely to be useful for quantifying training loads more accurately and designing training exercises and programs.
\end{abstract}

ARTICLE HISTORY

Accepted 1 October 2018

KEYWORDS

Pull-up training; sport-climbing; arm power; grip types

\section{Introduction}

Rock-climbing requires equilibrating and moving the entire body along routes across walls, boulders, and cliffs, using quadrupedal locomotion. It requires many physical (Baláś, 2017), psychological (Sanchez, 2017), technical (Baláš et al., 2014; Quaine, Martin, Leroux, Blanchi, \& Allard, 1996), and cognitive skills (Bourdin, Teasdale, \& Nougier, 1998; Epling, Blakely, Russel, \& Helton, 2017). These include the crucial capacities to exert strong fingertip forces on the holds and pull ups with the upper limbs to reach the next hold (Draper, Dickson, Blackwell, Priestley, Fryer, Marshall, Shearman, Hamlin, Winter \& Ellis, 2011; Watts, 2004).

Improving finger and arm capacities forms a preponderant part of a climber's training and several studies have demonstrated that these capacities are closely related to a climber's performance (Baláš, 2017; Grant, Hynes, Whittaker, \& Aitchison, 1996; Quaine \& Vigouroux, 2004; Quaine, Vigouroux, \& Martin, 2003; Watts, 2004). Concerning the climbers' elbow and shoulder capabilities, Draper et al. (2011) investigated and quantified the arm power developed by elite climbers (around 1350W) and novices (around 40W) during arm-jump exercises. Nevertheless, these values were estimated using large climbing holds while during training and climbing, climbers mainly use small holds. Concerning the climbers' finger and forearm muscle capabilities, several previous studies revealed that climbers have high capacities for exerting maximal forces at the fingertips (Cutts \& Bollen, 1993; Quaine et al., 2003; Vigouroux, Goislard de Monsabert \& Berton, 2015) and minimizing fatigue effects during intermittent repetition of intense finger-grip forces $(80 \%$ of maximal voluntary force, MVF) (Philippe, Wegst, Müller, Raschner, \& Burtscher, 2012; Quaine et al., 2003; Usaj, 2002; Vigouroux \& Quaine, 2006). Additional studies emphasised the importance of the hold depth for generating intense finger force and, by way of consequences, for climbing performances (Amca, Vigouroux, Aritan, \& Berton, 2012; Bourne, Halaki, Vanwanseele, \& Clarke, 2011). These authors characterized the hold depth effect on maximal grip force capabilities with polynomial relationship and showed a strong improvement in maximal grip force from very small (e.g. $0.4-0.5 \mathrm{~mm}$ hold depth) to intermediate hold depths (around $1.5 \mathrm{~cm}$ ) followed by a moderate improvement from intermediate to larger hold depths $(4 \mathrm{~cm})$. These previous studies described climbers'finger capabilities but were only investigated during static conditions while an important part of climbing and training movements were performed dynamically at the arms level.

To train their arm and finger capabilities, climbers usually perform pull-ups (Youdas et al., 2010). These exercises are also part of the usual training regimen for several other sports and previous analyses in the literature concerned non-climbers (Andersen, Fimland, Wiik, Skoglund, \& Saeterbakken, 2014; Antinori, Felici, Figura, Marchetti, \& Ricci, 1988; Koyama, Kobayashi, Suzuki, \& Enoka, 2010; Ricci, Figura, Felici, \& Marchetti, 1988). One major difference between pull-ups for climbing objectives compared to fitness is the use of various types of grips, including gym bars, as well as large and small climbing holds. However, it was not previously known how the type of grip influenced the pull-up exercise, although this information is needed to quantify the training loading on both the 
arms and fingers during these exercises. This lack of information prevented accurate quantification and design of climber's training programs. More generally, pull-ups exercise represents an interesting standardized paradigm to understand how the hold depth influences the biomechanical arm action (power, mechanical work, etc.) in sport-climbing and in turn, how arm movements impact the finger grip.

The aim of this study was thus to investigate mechanical parameters of pull-ups (especially the maximal forces applied, maximal power, and mechanical work) executed by climbers under various grip-type conditions. We hypothesized that pullup performance would decrease with grip depth, due to a decrease in finger grip force capacities and an increase in finger muscle fatigue, combined with increasing difficulty in controlling body swing during the pull-up movement.

\section{Methods}

\section{Participants}

Ten elite and higher-elite male climbers (according to the grouping abilities of Draper et al. (2016), ranging from French grade $7 \mathrm{c}$ to $8 \mathrm{~b}+$ ) volunteered to participate in the experiment (age: $21.4 \pm 2.6$ years; body weight: $65.95 \pm 5.9 \mathrm{~kg}$; height: $175.6 \pm 4.5 \mathrm{~cm}$; hand size: $19.2 \pm 0.9 \mathrm{~cm})$. The participants had all trained three times a week for at least five years. All participants did not present any injury to the hands or arms and were asked not to train the day before the experiment. The study was conducted with the formal approval of the local human care committee of Aix-Marseille University and the participants signed a voluntary participation form according to the University guideline.

\section{Experimental protocol}

After a warm-up (climbing 2-3 routes of sub-maximal difficulties) and enough time to familiarize themselves with the test equipment, participants were asked to perform a maximum number of pull-ups. For each pull-up, they were required to start with fullyextended arms and finish with the chin level with the hold. For each series, the participants were asked to perform the pull-ups "as fast as possible" and "as strongly as possible" until exhaustion. Six series of maximal pull-up were performed, corresponding to six different grip conditions: a large hold ( $>80 \mathrm{~mm}$ in depth), a gym-bar $(2.5 \mathrm{~mm}$ in diameter) and four small climbing holds (10 $\mathrm{mm}$ hold, $14 \mathrm{~mm}$ hold, $18 \mathrm{~mm}$ hold, $22 \mathrm{~mm}$ hold). Each series started with a 5 s static phase when the participant was hanging statically on the grip support with body and arm extended before starting the pull-ups. This static phase was used to evaluate the body mass of the participants (BM). Participants rested for at least fifteen minutes between each condition. As the participants were required to exert maximum effort repeatedly, the experiment was conducted on two non-consecutive days (separated by 5 days at maximum) to minimize the fatigue effect (3 grip conditions per experimental day). The experiment was conducted at a similar time on both days to limit the effect of circadian cycles. The conditions were randomized to minimize the fatigue and order effects.
Maximal voluntary finger force (MVF) was measured on the tested hold before starting the pull-ups under small climbing hold conditions $(10 \mathrm{~mm}, 14 \mathrm{~mm}, 18 \mathrm{~mm}$ and $22 \mathrm{~mm}$ ). Participants were asked to perform two static trials of maximal voluntary finger-force exertion with the right and left arm in turn. For this measurement, they were instructed to pull as hard as possible with one hand on the hold at the preferred elbow and shoulder angle. When necessary, an additional load $(10 \mathrm{~kg})$ was attached to the body to maintain it in a static position, especially when participants were able to exert a maximal force superior to their body weight. The MVF was estimated by summing the maximal forces recorded for the right and left arms. The ratio of the MVF values to the maximal force recorded during the pull-ups was calculated.

\section{Material}

A specially designed force platform (0-4000N, Sixaxes, Argenteuil, France) was used to measure the vertical force applied by climbers on the grip support (either a climbing hold or a gym-bar). The platform consisted of a rigid metal plate mounted on four transducers using strain gauges. Linearity, hysteresis, and calibration of the force platform were monitored several times during the overall experimental session. The platform was fixed on a rigid support $2 \mathrm{~m}$ above the floor, with a large space under it to prevent climbers from touching the wall or anything during the exercise (Figure 1). The six grip conditions were randomly tested. A commercial hangboard (Transgression-Eva Lopez, Spain) was fixed to the vertical force platform to test the climbing hold conditions. The depth of the large climbing hold was larger than the length of the fingers from the metacarpophalangeal joints to the fingertips (i.e. $>80 \mathrm{~mm}$ in depth). The four small climbing holds consisted of ledges of similar shapes but with depths of $10 \mathrm{~mm}, 14 \mathrm{~mm}, 18 \mathrm{~mm}$ and $22 \mathrm{~mm}$. In all conditions, the climbers were free to hold the grip support with their preferred grip technique (i.e. slope or crimp) but were not allowed to use the thumb with a full crimp grip technique. Consequently, the thumb was only used to grip the gym-bar.

Electromyographic (EMG) signals were recorded from the Biceps brachii (BB), Triceps brachii (TB), finger extensors (Extensor digitorum communis, FE), and finger flexors (Flexor digitorum superficialis and profundus, FF) of the right arm. After an appropriate skin preparation, $\mathrm{Ag}-\mathrm{Cl}$ electrodes $(9 \mathrm{~mm}$ diameter, Oxford Instruments Medical, Surrey, UK) were attached to the muscle bellies at an inter-electrode distance of $2 \mathrm{~cm}$. For $\mathrm{BB}$ and TB muscles, the electrodes were positioned according to the recommendations of SENIAM (Hermens, Freriks, Disselhorst-Klug, \& Rau, 2000). To ensure the correct placement of the electrodes and obtain the maximal activation of these two muscles, $6 \mathrm{~s}$ maximal static flexions and extensions of the elbow joint positioned at $90^{\circ}$ were performed to specifically activate the BB and TB muscles respectively.

For FE and FF muscles, the electrodes were positioned as described in Vigouroux, Goislard de Monsabert, and Berton (2015). Special attention was paid to minimize cross-talk with the nearby wrist flexors and extensors. For FF, this was done by asking subjects to alternate between flexing the fingers with a relaxed wrist and flexing the wrist with relaxed fingers. 

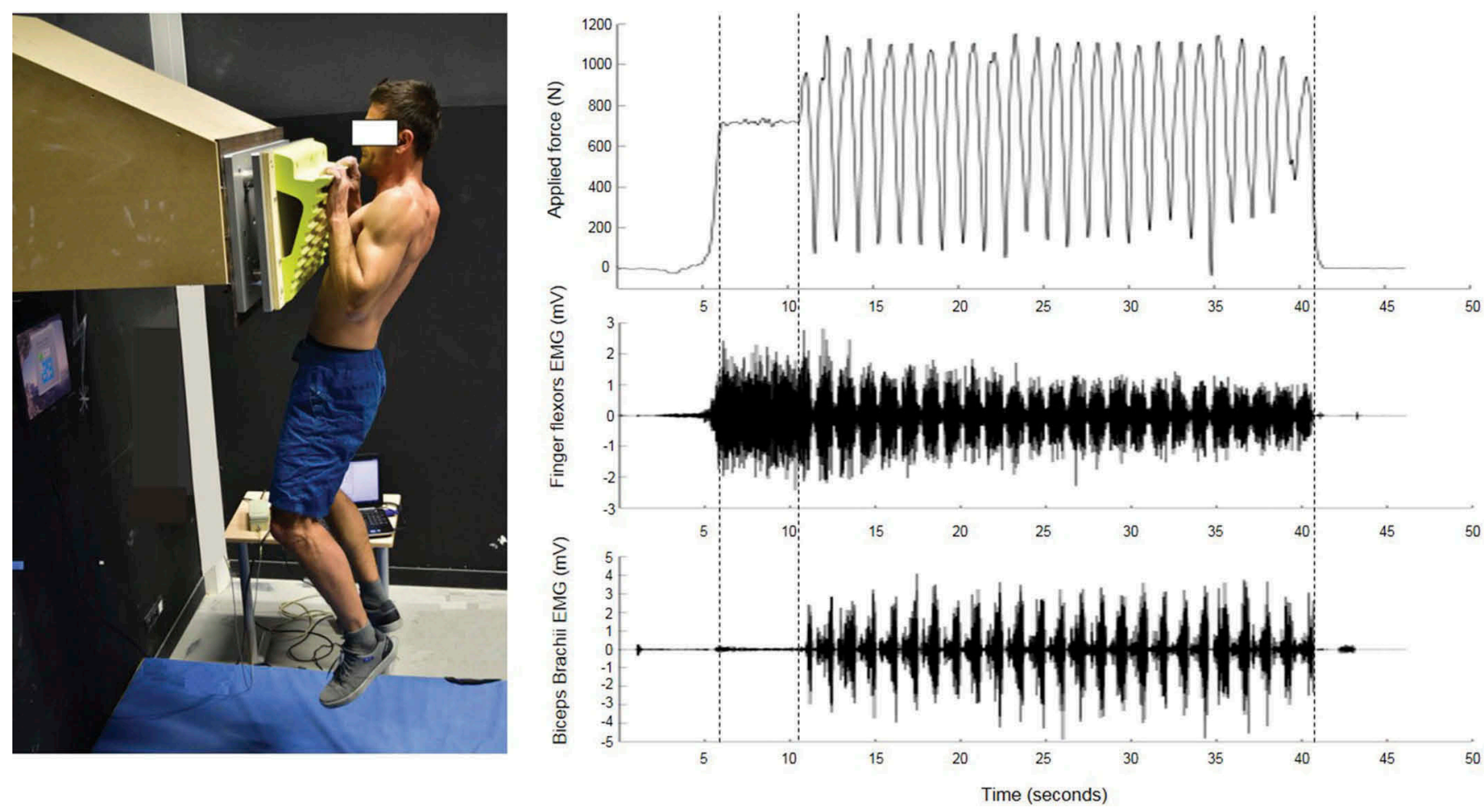

Figure 1. Experimental setup photo and raw data. The picture on left shows the vertical platform fixed on a rigid support and equipped with the commercial hangboard (yellow hold) used to test the climbing hold conditions. The graphs on the right show representative data of the vertical force (upper panel), Finger flexor EMG (middle panel), and Biceps brachii EMG (lower panel), recorded during one pull-up series. The moment when the subject was hanging immobile on the hold before starting the pull-ups is clearly visible (between the two dotted lines).

Experimenters then checked that the FF signal was minimal during wrist flexions and maximal during finger flexions. For $\mathrm{FE}$, cross-talk was verified by comparing maximal extension of the fingers with maximal extension of the wrist and simultaneous flexion of the fingers. The maximal elbow flexion and extension, as well as the maximal finger flexion and extension were further used to normalize EMG signals.

Force and EMG data were amplified and sampled synchronously at $2000 \mathrm{~Hz}$ using the Biopac MP150 system (Biopac Systems Inc., Goleta, (A) and the associated software (Acknowledge, Biopac Systems Inc., Goleta, CA). Figure 1 illustrates a representative set of data gathered during the pull-up exercise.

\section{EMG data analysis}

EMG signals were treated and analysed to quantify: i) the level of fatigue in the finger flexor muscles responsible for grip during the pull-ups and ii) the activation level of the recorded muscles and the cocontraction index of the finger muscles during the entire trial. The EMG data were filtered (Butterworth, fourth-order, band-pass, cut-off frequency: $20-450 \mathrm{~Hz}$ ) prior to all analyses. The EMG treatment for the analysis of finger flexor fatigue was inspired by Quaine et al. (2003): the EMG signal mean power frequency (MPF) was computed by performing a Fast Fourier Transformation on a $250 \mathrm{~ms}$ window centred on the peak force of each pull-up. For each condition, the evolution of finger flexor MPF was evaluated using a linear regression between MPF and the number of pull-up repetitions. The slope of this linear regression was used as an index of each subject's finger flexor fatigue during each condition.

The method for evaluating the activation level during the trials was based on Amarantini \& Martin (2004): the initial filtered EMG signals were full-wave rectified and low-pass filtered (Butterworth, fourth-order, cut-off frequency: $4 \mathrm{~Hz}$ ). Then the signal of each muscle was normalized with the maximal value recorded either during the functional movement or during the pull-ups. The cocontraction index between the finger flexors and extensors was then computed using the Winter (1990) equations:

$$
\text { cocontraction index }=\frac{2 . E M G_{F E}}{E M G_{F E}+E M G_{F F}}
$$

where $E M G_{i}$ is the treated EMG signal of the $\mathrm{i}^{\text {th }}$ muscle. The mean cocontraction index during the entire trial was then computed for each condition. For the BB muscles, the mean activation level was computed throughout the trials.

\section{Force data analysis}

Force data was low-pass filtered (Butterworth, fourth-order, cut-off frequency: $3 \mathrm{~Hz}$ ). The maximum force applied by each participant during the pull-up series was detected. For the hold grip conditions $(10 \mathrm{~mm}, 14 \mathrm{~mm}, 18 \mathrm{~mm}, 22 \mathrm{~mm})$, the maximal force applied during pull-ups was expressed as a ratio of the MVF of the corresponding hold depth. Based on Newton's second law $\left(\sum \vec{F}=m . \vec{a}\right)$ and using successive integration of the force recordings, power and mechanical work were calculated using the following equations: 


$$
P(t)=F(t) \cdot\left(\frac{\Delta t \cdot(a(t+\Delta t)+a(t)}{2}\right)
$$

where

$$
\begin{gathered}
a(t)=\frac{F(t)+B M \cdot g}{B M} \\
W(t)=\frac{\Delta t \cdot(P(t+\Delta t)+P(t))}{2}
\end{gathered}
$$

\section{Statistics}

Mean and standard deviation ( \pm ) among subjects were used to describe the results. Repeated measure ANOVAs and Tukey's post-hoc tests were used to investigate the effect of the griptype conditions (6 different grip conditions: $10 \mathrm{~mm}, 14 \mathrm{~mm}$, $18 \mathrm{~mm}, 22 \mathrm{~mm}$, large-hold, and gym-bar) on the number of pull-ups, the summed mechanical work, maximal power, maximal force applied, the slope of the finger flexor EMG mean power frequency, the EMG cocontraction index of finger muscles, and the mean activation level of the BB. As the homogeneity of variance and data normality were not met for some of these variables, the statistical conclusions obtained by the ANOVAs were systematically controlled by performing a nonparametric Friedman test. In all cases, the non-parametric tests gave the same significant results as the ANOVA. For clarity, only the ANOVA results were included in the article. The statistical significant threshold was fixed at $p<0.05$.

A 2nd-order polynomial regression was performed to model the evolution of the summed mechanical work, maximal power, and maximal force applied, in function of hold depth. To perform this regression model, these variables for the four small climbing hold conditions $(10 \mathrm{~mm}, 14 \mathrm{~mm}, 18 \mathrm{~mm}$, and $22 \mathrm{~mm}$ ) were expressed as a ratio of the values obtained with the large climbing hold.

\section{Results}

\section{Number of pull-ups and maximal force}

The results (Table 1 ) revealed an effect of the grip condition on the number of pull-ups $(F(5,45)=61.7 ; p<0.001)$. The number of pull-ups was not significantly different between the large-hold and gym-bar conditions ( $p=0.89$ ), but decreased with the smallest holds ( $p<0.001$ for $10 \mathrm{~mm}$ compared to $18 \mathrm{~mm}-22 \mathrm{~mm}$-large-gym, $14 \mathrm{~mm}$ compared to $22 \mathrm{~mm}$-large-gym, $18 \mathrm{~mm}$ compared to large-gym, and $22 \mathrm{~mm}$ compared to large hold and gym-bar). Among the participants, the highest recorded results were 13 pull-ups on the $10 \mathrm{~mm}$ hold and 38 pull-ups on the gym-bar. The lowest observed results were 2 pull-ups on the $10 \mathrm{~mm}$ hold and 22 pull-ups on the gym-bar.

To illustrate the force applied during pull-ups, Figure 2 presents typical recordings of force data from a representative subject in the $14 \mathrm{~mm}$ and gym-bar conditions. On this recording, the amplitude of the maximum and minimum peaks was greater in the gym-bar condition. Besides the different amplitude values, it is important to observe the typical shape of the curves: pull ups on the $14 \mathrm{~mm}$ hold were characterized by a single maximal force peak, while those on the gym-bar exhibited a double peak.

The maximal force applied during the pull-up series (Table 1 and Figure 3(b)) decreased with the grip type $(F(5,45)=62.8 ; p<0.001)$. For example, the maximal applied force amounted to $1274.7 \pm 121.1 \mathrm{~N}(2.0 \pm 0.2$ times body weight) on the gym-bar, but only $823.7 \pm 123.2 \mathrm{~N}(1.3 \pm 0.1$ times body weight) on the $10 \mathrm{~mm}$ hold. The maximal applied force was not significantly different between the large hold and the gym-bar but decreased significantly with the small holds $(p<0.001$ for $10 \mathrm{~mm}$ compared to $18 \mathrm{~mm}-22 \mathrm{~mm}$-large-gym, $14 \mathrm{~mm}$ compared to large-gym, $18 \mathrm{~mm}$ compared to large-gym, $22 \mathrm{~mm}$ compared to large-gym). In the small hold conditions, the ratio of maximal applied force to MVF (Table 1) varied according to the conditions $(F(3,27)=3.5 ; p<0.03)$. The Tukey post-hoc revealed that this significant effect was mainly due to the $22 \mathrm{~mm}$ condition rather than the others $(p<0.05)$. This ratio amounted to $0.88 \pm 0.09$ with the $22 \mathrm{~mm}$, whereas it amounted to 0.94 for the other conditions.

\section{EMG indexes}

The statistical analysis revealed a significant effect of the grip type on the slope of the finger flexor $\operatorname{MPF}(F(5,45)=6.1$; $p<0.001$ ) (Table 1). The results showed a steeper slope for $10 \mathrm{~mm}$ and $14 \mathrm{~mm}$ climbing holds in comparison to other grip conditions. The slope of MPF with the large hold appeared steeper compared to the gym-bar.

\begin{tabular}{|c|c|c|c|c|c|}
\hline $\begin{array}{l}\text { Grip } \\
\text { conditions }\end{array}$ & Number of pull-ups & $\underset{(* * *)}{\text { Maximal power/BM }}$ & $\begin{array}{l}\text { Maximal force/MVF } \\
\qquad\left({ }^{*}\right)\end{array}$ & $\begin{array}{l}\text { Slope of the FF EMG mean power frequency } \\
\qquad\left(^{* *}\right)\end{array}$ & $\begin{array}{l}\text { Cocontraction index } \\
\left(^{* * *}\right)\end{array}$ \\
\hline $10 \mathrm{~mm}$ & $6.6 \pm 3.6 \neq$ & $6.5 \pm 3.0 \neq$ & $0.93 \pm 0.09$ & $-0.02 \pm 0.02$ & $0.43 \pm 0.16$ \\
\hline $14 \mathrm{~mm}$ & $11.4 \pm 4.2 \neq$ & $9.3 \pm 1.8 \neq \alpha$ & $0.94 \pm 0.05$ & $-0.01 \pm 7.10^{-3}$ & $0.45 \pm 0.17$ \\
\hline $18 \mathrm{~mm}$ & $15.6 \pm 4.5 \neq a$ & $10.9 \pm 1.5 \neq a$ & $0.94 \pm 0.08$ & $-5.10^{-3} \pm 4.10^{-3} a$ & $0.46 \pm 0.18 \#$ \\
\hline $22 \mathrm{~mm}$ & $18.4 \pm 6.2 \neq a$ & $12.3 \pm 1.7 \neq a$ & $0.88 \pm 0.09 *$ & $-7.10^{-3} \pm 5.10^{-3} a$ & $0.52 \pm 0.11$ \\
\hline Large-hold & $27.7 \pm 7.7 \mathrm{a}$ & $16.0 \pm 1.9$ & l & $-5.10^{-3} \pm 3.10^{-3} a$ & $0.64 \pm 0.13$ \\
\hline Gym-bar & $29.4 \pm 5.5 x$ & $16.3 \pm 2.3 a$ & / & $-3.10^{-3} \pm 2.10^{-3} a$ & $0.44 \pm 0.15$ \\
\hline
\end{tabular}

Table 1. Mean $( \pm S D)$ of the number of pull-ups, maximal power to body-mass ratio, maximal force applied to maximal voluntary force ratio, the slope of the finger flexor EMG mean power frequency, and the cocontraction index between finger flexors and extensors.

a different $(<0.05)$ from the $10 \mathrm{~mm}$ hold condition

$\neq$ different $(<0.05)$ from the gym-bar condition

\# different from all the other conditions

*** significant effect of grip conditions $<0.0001$

* significant effect of grip conditions $<0.05$ 

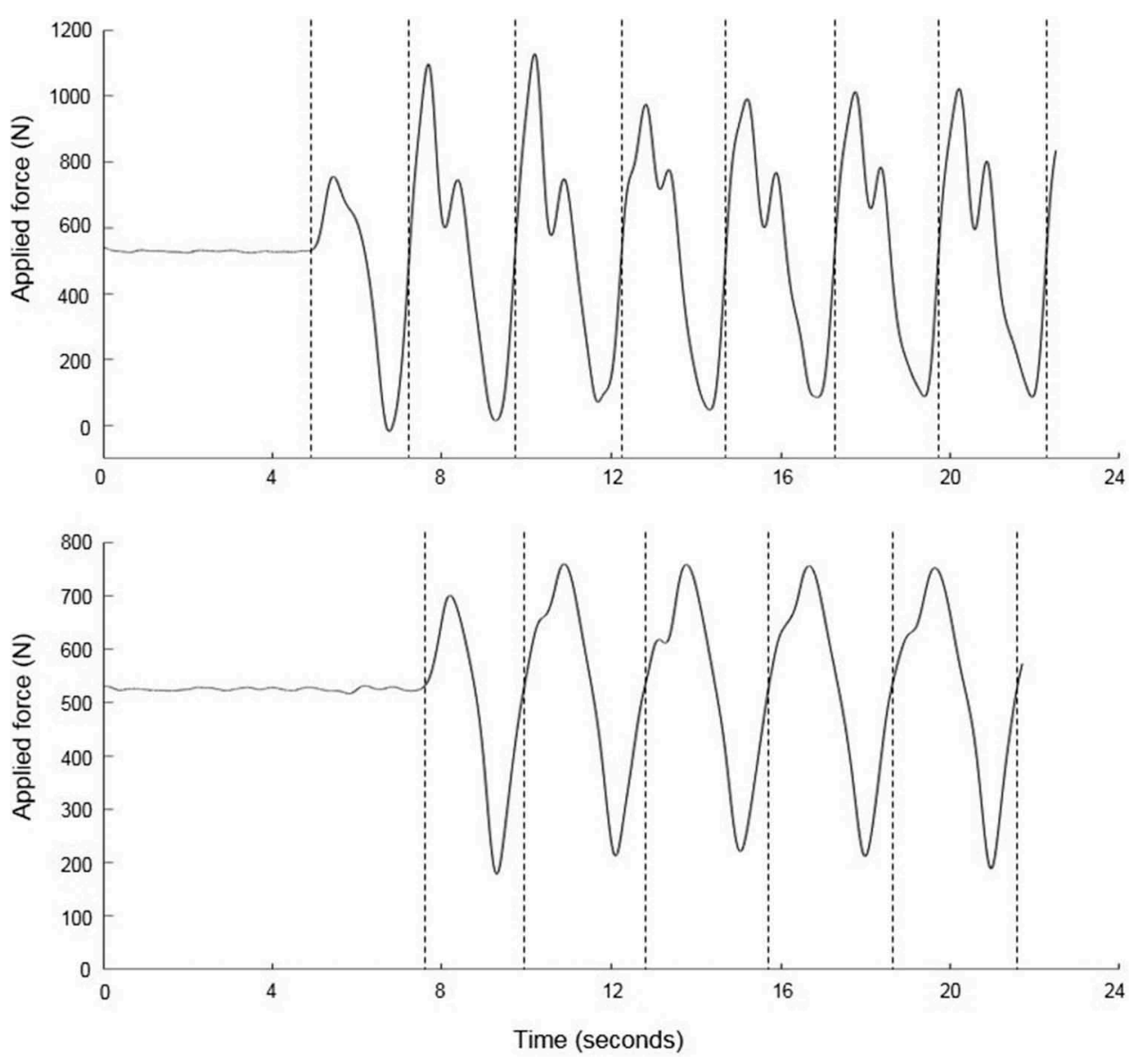

Figure 2. "Example of force recorded during pull-ups by a representative participant on the gym-bar (upper panel) and 14mm hold (lower panel). The dotted vertical lines indicate each pull-up cycle."

The statistical analysis for the cocontraction index (Table 1) revealed an effect of the grip type $(F(5,45)=9.8 ; p<0.001)$. The lowest cocontraction indexes were observed for the $10 \mathrm{~mm}$ and gym-bar conditions and the highest indexes for the large-hold. For climbing hold conditions, the cocontraction index increased gradually but non-significantly from $10 \mathrm{~mm}$ to the large hold. The post-hoc test revealed that the large hold condition was different from all the other conditions $(p<0.05)$.

$\mathrm{BB}$ activation level results revealed a significant effect of the grip type $(F(5,45)=4.67 ; p<0.002)$. The post-hoc revealed that the $\mathrm{BB}$ activation levels with the $10 \mathrm{~mm}$ hold $(0.70 \pm 0.14)$ were significantly lower $(p<0.05)$ than with the $22 \mathrm{~mm}$ hold $(0.87 \pm 0.12)$ and the gym-bar $(0.95 \pm 0.11)$. BB activation levels with the $14 \mathrm{~mm}, 18 \mathrm{~mm}$, and large hold amounted to $0.84 \pm 0.15$, $0.81 \pm 0.17,0.83 \pm 0.14$, respectively.

\section{Maximal power and summed mechanical work}

The maximal power developed by climbers (Figure 3(c)) amounted to $1107.5 \pm 148.5 \mathrm{~W}$ on the gym-bar and $1050.6 \pm 147.6 \mathrm{~W}$ on the large-hold, with no significant difference $(p=0.99)$. Maximal power on the $10 \mathrm{~mm}$ hold was only $425.4 \pm 208.8 W$. The statistical analysis revealed an effect of the grip type $(F(5,45)=53.9 ; p<0.001)$. Post-hoc analysis showed that the $10 \mathrm{~mm}$ hold was significantly different $(p<0.01)$ from all the other conditions; the $14 \mathrm{~mm}$ condition was different $(p<0.01)$ from the $22 \mathrm{~mm}$, large hold, and gym-bar; the $18 \mathrm{~mm}$ condition was different $(p<0.01)$ from the large hold and gym-bar; the $22 \mathrm{~mm}$ was different $(p<0.01)$ from the large-hold, and gym-bar. The maximal power to body-weight ratio ranged from $6.5 \mathrm{~W} . \mathrm{kg}-1$ on the $10 \mathrm{~mm}$ hold to $16.3 \mathrm{~W} . \mathrm{kg}-1$ on the gym-bar (Table 1).

The results revealed an effect of grip type on the summed mechanical work $(F(5,45)=111.0 ; p<0.001)$. There was no significant difference in summed mechanical work between the large-hold and gym-bar conditions $(p=0.41)$, but values were significantly lower for the smaller holds $(p<0.01)$. Summed mechanical work ranged from $1202.9 \pm 1027.7 \mathrm{~J}$ on the $10 \mathrm{~mm}$ hold to $9059.9 \pm 1348.7 \mathrm{~J}$ on the gym-bar. Post-hoc analysis revealed significant differences $(p<0,01)$ between the $10 \mathrm{~mm}$ hold condition and $18 \mathrm{~mm}, 22 \mathrm{~mm}$, large-hold, and gym-bar; the $14 \mathrm{~mm}$ was different $(p<0,01)$ from the $18 \mathrm{~mm}, 22 \mathrm{~mm}$, large hold, and gym-bar; the $18 \mathrm{~mm}$ was different $(p<0,01)$ from the $22 \mathrm{~mm}$, large hold, and gym-bar; and the $22 \mathrm{~mm}$ was different $(p<0,01)$ from the large hold, and gym-bar.

\section{Polynomial regressions}

Figure 4 presents the polynomial regression used to model the relationship between hold depth and maximal power, summed mechanical work, and maximal force applied, expressed as a ratio of the values obtained in the large-hold condition. $R^{2}$ values produced coefficients close to $1(0.996,0.997$, and 0.999 for 


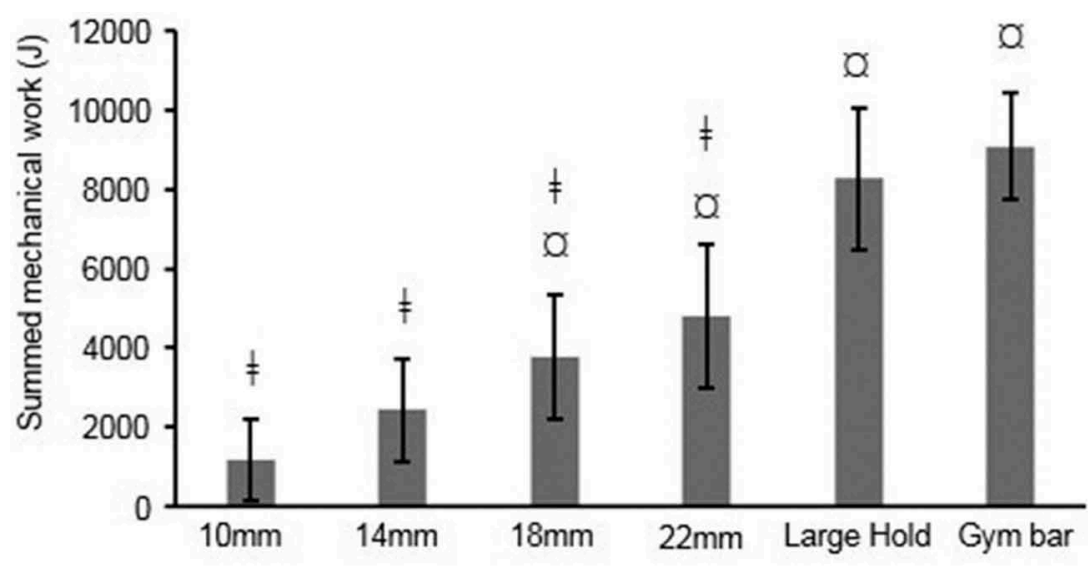

\section{A}
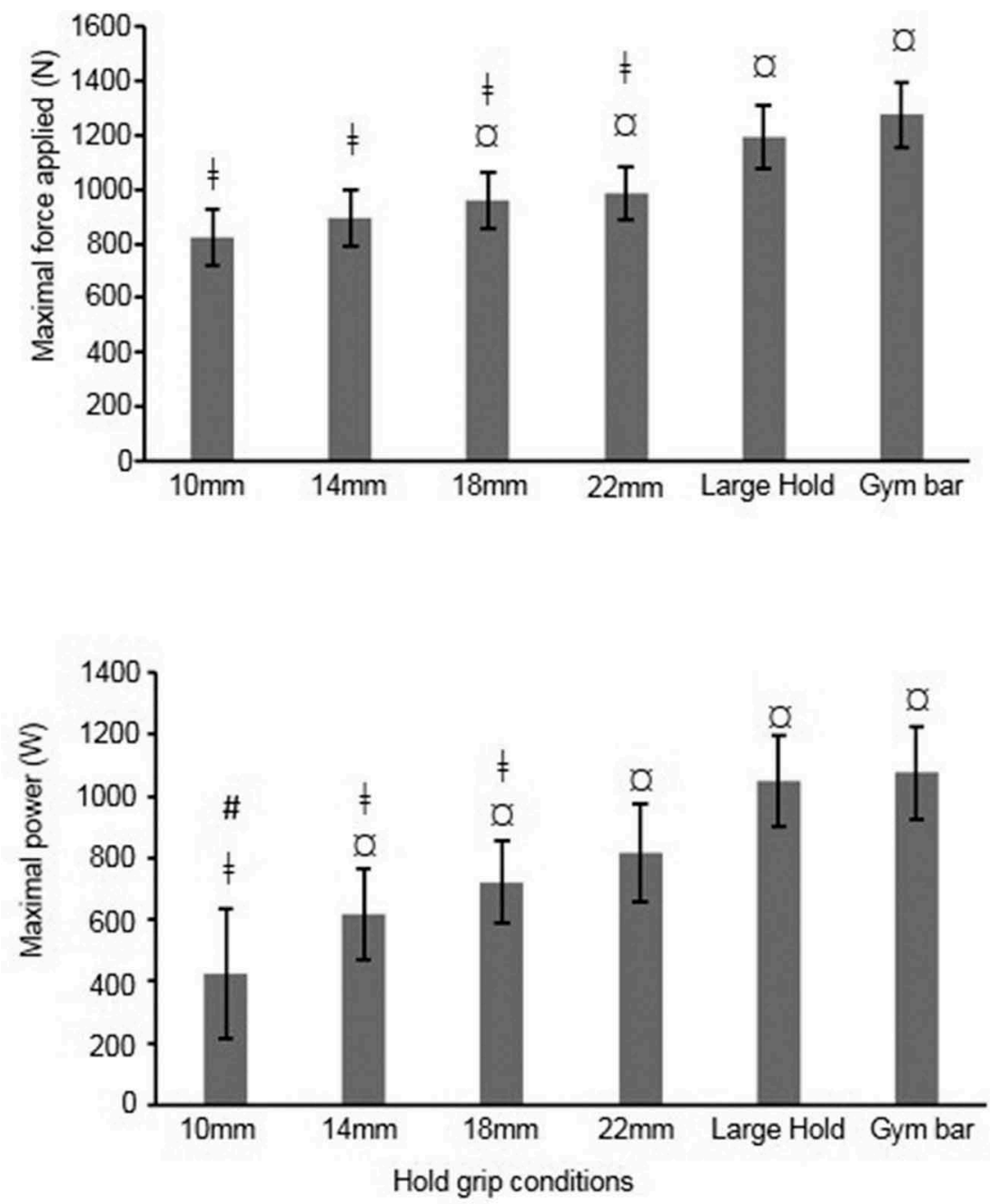

Figure 3. Mean $( \pm S D)$ of the summed mechanical work (a), maximal applied force during pull-ups (b), and maximal power (c) for each grip condition. $x$ indicates significant difference $(0.05)$ with the $10 \mathrm{~mm}$ hold condition. \# indicates significant difference with the gym-bar condition. \# indicates significant difference with all other conditions.

summed mechanical work, maximal power, and maximal force applied, respectively). The regressions exhibited different evolutions according to the variables. Maximal power had the steepest curve, with the highest ratio for the 2nd-order coefficient, while the evolution of maximal force applied was quasi-linear. The maximal forces applied varied considerably between the largeand small-hold conditions while the maximal power and mechanical work influences. 


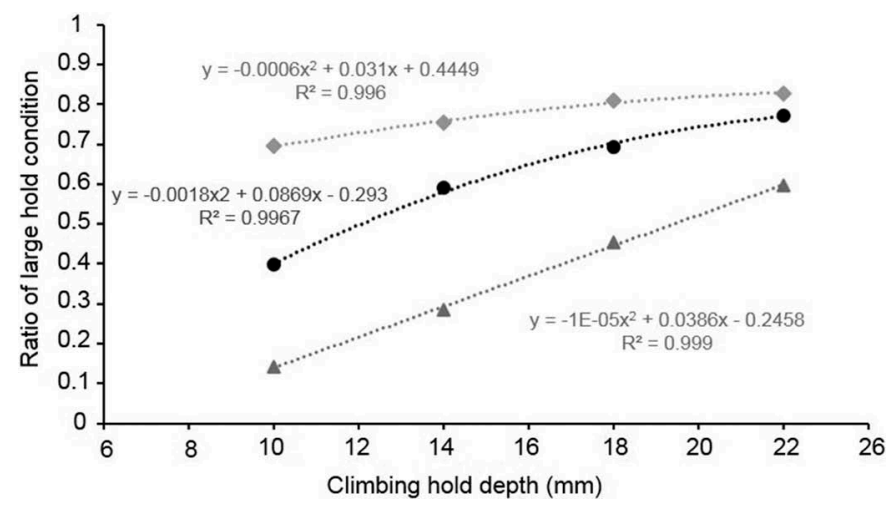

Figure 4. "Regression models of the effect of hold depth on summed mechanical work (grey triangles), maximal power (black circles) and maximal force applied (grey diamonds). Results are expressed as a percentage of those obtained with the large-hold condition."

\section{Discussion}

This study quantified the effect of the grip types on pull-ups by analysing the vertical force applied on the grip support and EMG of finger and arm muscles. The overall results of this study revealed that the grip conditions affected pull-up biomechanical performances. In particular, the small climbing holds had a strong negative impact on maximal power and mechanical work compared to the large climbing hold and gym-bar. The factors behind these results were discussed above.

A first important finding of this study concerns the comparison between the large climbing hold and the gym-bar conditions. Our results indicated that pull-ups on a gym-bar or large climbing hold is a similar exercise from a performance standpoint. This may suggest that training on gym bar or on large climbing hold would have the same impact on climbers. Nevertheless, this conclusion should be treated with caution since the large climbing hold required a higher cocontraction index in the forearm muscles, probably to increase the stiffness of the wrist and to secure the hold grip. Concomitantly, increased finger-flexor muscle fatigue was also generated with the large climbing hold. These differences in EMG results may be explained by the behaviours of the climbers when executing the pull-ups. With good grips (either the large hold or the gymbar), the participants executed fast eccentric phases, using muscle elasticity, body-movement coordination (knee/hip flexions), and uncontrolled body swings. These behaviours were detectable in the force recordings on the gym-bar and large hold conditions, where double/triple force peaks were systematically observed, while only one force peak was usually observed on the smaller climbing holds (Figure 2). The observed differences in EMG results between the gym-bar and large-hold suggested that body movements may have variable consequences at grip level, resulting in increased forearm muscle cocontraction and fatigue with the large climbing hold compared to the gym-bar. This information is important for climbing trainers, who usually aim to train the upper-limb segments in combination to mimic the behaviour of the upper-limbs during sport-climbing. From this standpoint, doing pull-ups on a large climbing hold is clearly more specific than using a gym-bar, as the grip action is more similar to rock-climbing.
Comparing our power results with the gym-bar and large hold with those in the literature, it is interesting to note that the measured values were $20 \%$ lower than those estimated using arm jump exercises (Draper et al., 2011) but nearly 2.5 times higher than those reported by Koyama et al. (2010). Differences with the findings of Koyama et al. (2010) may be due to the fact that the pull-ups were executed using an upper limb fitness machine, where the participants were seated while pulling up a weight. Difference with Draper et al. (2011) may have originated from several factors. First, we hypothesize that the ballistic nature of the arm jump exercise allowed participants to develop higher power, since they were not required to stay on the hold and execute successive pull-ups. Nevertheless, it could be also argued that the arm jump exercise mainly involves concentric muscle contractions only, while eccentric and plyometric contractions are used during pull-ups. The latter types of muscle contractions involve considerable muscle elasticity and tendon stiffness and are expected to increase power during pull ups, in contrast to the $20 \%$ lower results. A final explanation for the observed differences in results may be the power calculation method used in this study. In Draper et al. (2011), power was deducted from the height of the jump using a calculation established for and generally applied to the lower limbs, while our power calculation was directly based on the force measurements. Nevertheless, the several signal integration and filtering steps may also have an influence on the method proposed here, indicating that the power developed during upper-limb movements requires further investigation, using both kinematics (to deduct the velocity directly) and force measurements.

Another notable finding of this study is the effect of climbing hold depth on the pull-ups. A decrease in hold depth led to a considerable decrease in pull-ups performances. One obvious explanation of this results is the decrease in the maximal finger force capacities resulting from the reduction in hold depth, previously observed and modelled by Amca et al. (2012). Nevertheless, a second motor control factor may also contribute to explain the observed results since the maximal force applied during the pull-ups only represented $88 \%$ to $94 \%$ of the maximal finger force capacities measured during the static maximal finger force contractions. In other words, the climbers apparently did not use their entire finger force capacities during the pull-ups. Using a force level intensity below the maximal capacity may be attributed to the wellknown force-deficit principle, previously observed when exerting maximal force with the fingers (Li, Latash, \& Zatsiorsky, 1998; Martin, Zatsiorsky, \& Latash, 2011; Vigouroux, Rossi, Foissac, Grélot, \& Berton, 2011). These observations led to several findings: first, maximal finger force capacities are not fully used during pull-ups. Second, the evolution of the maximal force applied during pull-ups according to hold depth did not reflect that of maximal finger-force capacity since this force deficit is not constant according to the hold depth. On a more fundamental level, it is interesting to observe that, even a basic pull-up exercise involves a degree of upperlimb movement control. To fully understand this phenomenon, further studies focused on the force-deficit during more complex climbing movements should be conducted. 
The impact of hold depth on the maximal power was higher than its impact on maximal applied force. This revealed that, additionally to the maximal force applied, the velocity of the pull-ups decreased with hold depth. This may be explained by the fact that it is necessary to restrict body swings and other movements when performing pull-ups on the small climbing holds, to avoid losing the grip. The participants probably thus reduced the pull-up velocity to minimize swinging and restrict body movement coordination. This conclusion was supported by the observation that few double force peaksswing) were measured during pull-ups/swing) were measured during pull-ups on the small holds (e.g. Figure 2). Furthermore, the EMG cocontraction index decreased concomitantly with climbing hold depth, revealing reduced control of wrist stiffness. This finding is difficult to discuss but may be related to i) a lesser need to control wrist stiffness compared to the large climbing hold condition where body coordination/movements were present ii) a diminished action of antagonist muscles to facilitate the finger flexors mechanical action. This shows that pull-up training on climbing holds offers the potential for climbers to train their overall upper-limb chain at the same time and, concomitantly, enhance the motor control aspects of upper limb movements.

The parameter most affected by the decrease in climbing hold depth was the summed mechanical work (and, obviously, the associated number of pull-ups). In addition to the explanations above (body equilibrium control, decrease in finger force capability, and force-deficit), there is also a forearm muscle fatigue effect revealed by the evolution of the EMG MPF. This forearm fatigue results from the repeated exertion of finger forces on the holds during the entire exercise of pull-ups. This indicates that pull-ups on small climbing holds also represent a good exercise for enhancing forearm fatigue resistance as well as maximal finger force capacity and upper-limb coordination to control body swing/equilibrium. Nevertheless, the EMG results of the Biceps brachii and the decreased performances showed that the muscles mobilizing the elbow and shoulder were less and less solicited as climbing-hold depths decreased. Trainers should thus choose the depth of the holds carefully, to suit the targeted capacities and objectives of the pull-up exercise. To help this training process, the polynomial regressions modelled the decrease in performance related to the reduction of climbing hold depth(Figure 4). Using these regressions, one can estimate the maximal force, the power, the mechanical work developed during pull-ups exercises according to the hold depth.

To summarize, this study revealed that climbing hold depth and grip type had a considerable effect on the performance of pull-ups. In particular, maximal force, power, and mechanical work were affected to different extents by the grip type. Our results quantified and modelled this effect, revealing that maximal finger force capacities, finger muscle fatigue, and the level of finger cocontraction developed with the grip type used contributed to explaining the difference in performance. Moreover, we suggest that the grip type generates different body/upper limb coordination strategies, to be confirmed by a detailed kinematic and EMG analysis of the shoulder, back, and elbow muscles. Since pull-ups are widely used in sport-climbing training, the current findings are crucial and could be used to better design the pull-ups exercise in function of the purchased training objectives. From a fitness training standpoint, this study is the first to quantify concomitantly power, mechanical work, and the force applied on a gym-bar during pull-ups. These data will be useful for integrating pull-ups into a global training program and relating these muscle loads to other fitness exercises.

\section{Acknowledgments}

Authors would like to thank Marie Raymaekers and Valentin Bowman for their help in the experimentation performance.

\section{Disclosure statement}

No potential conflict of interest was reported by the authors.

\section{References}

Amca, A. M., Vigouroux, L., Aritan, S., \& Berton, E. (2012). Effect of hold depth and grip technique on maximal finger forces in rock climbing. Journal of Sports Sciences, 30, 669-677.

Andersen, V., Fimland, M. S., Wiik, E., Skoglund, A., \& Saeterbakken, A. H. (2014). Effects of grip width on muscle strength and activation in the lat pull-down. Journal of Strength and Conditioning Research., 28, 1135-1142.

Antinori, F., Felici, F., Figura, M., Marchetti, M., \& Ricci, B. (1988). Joint Moments and work in Pull-ups. Journal of Sports Medicine and Physical Fitness., 28, 132-137.

Amarantini, D., \& Martin, L., (2004). A method to combine numerical optimization and EMG data for the estimation of joint moments under dynamic conditions. Journal of Biomechanics, 37, 1393-1404.

Baláš, J. (2017). Muscular strength and endurance in climbers. In L. Seifert, P. Wolf, \& A. Schweizer (Ed.), pp 147-163. The science of climbing and mountaineering. Oxford: Routledge.

Baláš, J., Panáčková, M., Jandová, S., Martin, A. J., Strejcová, B., Vomáčko, L. ... Draper, N. (2014). The effect of climbing ability and slope inclination on vertical foot loading using a novel force sensor instrumentation system. Journal of Human Kinetics., 30, 75-78.

Bourdin, C., Teasdale, N., \& Nougier, V. (1998). Attentional demands and the organization of reaching movements in rock climbing. Research Quarterly for Exercise and Sport, 69, 406-410.

Bourne, R., Halaki, M., Vanwanseele, B., \& Clarke, J. (2011). Measuring lifting forces in rock climbing: Effect of hold size and fingertip structure. Journal of Applied Biomechanics, 27, 40-46.

Cutts, A., \& Bollen, S. R. (1993). Grip strength and endurance in rock climbers. Proceedings of the Institution of Mechanical Engineers, Part H: Journal of Engineering in Medicine, 207, 87-92.

Draper, N., Dickson, T., Blackwell, G., Priestley, S., Fryer, S., Marshall, H., \& Ellis, G. (2011). Sport-specific power assessment for rock climbing. Journal of Sports Medicine and Physical Fitness., 51, 417-425.

Draper, N., Giles, D., Schöffl, V., Konstantin, F., Watts, P., Wolf, P., ... Abreu, E. (2016). Comparative grading scales, statistical analyses, climber descriptors and ability grouping: International Rock Climbing Research Association position statement. Sports Technology. doi:10.1080/19346182.2015.1107081

Epling, S., Blakely, M., Russel, P., \& Helton, W. (2017). Interference between a fast-paced spatial puzzle task and verbal memory demands. Experimental Brain Research. doi:10.1007/s00221-017-4938-z

Grant, S., Hynes, V., Whittaker, A., \& Aitchison, T. (1996). Anthropometric, strength, endurance and flexibility characteristics of elite and recreational climbers. Journal of Sports Sciences, 14, 301-309.

Hermens, H. J., Freriks, B., Disselhorst-Klug, C., \& Rau, G. (2000). Development of recommendations for SEMG sensors and sensor placement procedures. Journal of Electromyography and Kinesiology, 10, 361-374.

Koyama, Y., Kobayashi, H., Suzuki, S., \& Enoka, R. M. (2010). Enhancing the weight training experience: A comparison of limb kinematics and EMG 
activity on three machines. European Journal of Applied Physiology, 109, 789-801.

Li, Z. M., Latash, M. L., \& Zatsiorsky, V. M. (1998). Force sharing among fingers as a model of the redundancy problem. Experimental Brain Research, 119, 276-286.

Martin, J. R., Zatsiorsky, V. M., \& Latash, M. L. (2011). Multi-finger interaction during involuntary and voluntary single force changes. Experimental Brain Research, 208, 423-435.

Philippe, M., Wegst, D., Müller, T., Raschner, C., \& Burtscher, M. (2012). Climbing-specific finger flexor performance and forearm muscle oxygenation in elite male and female sport climbers. European Journal of Applied Physiology, 112, 2839-2847.

Quaine, F., Martin, L., Leroux, M., Blanchi, J. P., \& Allard, P. (1996). Effect of initial posture on biomechanical adjustments associated with a voluntary leg movement in rock climbers. Archives of Physiology and Biochemistry, 104, 192-199.

Quaine, F., \& Vigouroux, L. (2004). Maximal resultant four fingertip force and fatigue of the extrinsic muscles of the hand in different sport climbing finger grips. International Journal of Sport Medicine, 25, 634-637.

Quaine, F., Vigouroux, L., \& Martin, L. (2003). Finger flexors fatigue in trained rock climbers and untrained sedentary subjects. International Journal of Sports Medicine, 24, 424-427.

Ricci, B., Figura, F., Felici, M., \& Marchetti, M. (1988). Comparison of male and female functional capacity in pull-ups. Journal of Sports Medicine and Physical Fitness., 28, 168-174.
Jones, G., \& Sanchez, J. G. (2017). Psychological processes in the sport of climbing. In L. Seifert, P. Wolf, \& A. Schweizer (Ed.), The science of climbing and mountaineering. Oxford: Routledge. pp 244-256.

Usaj, A. (2002). Differences in the oxygenation of the forearm muscle during isometric contractions in trained and untrained subjects. Cellular and Molecular Biology Letters, 7, 375-377.

Vigouroux, L., Goislard de Monsabert, B., \& Berton, E. (2015). Estimation of hand and wrist muscle capacities in rock-climbers. European Journal of Applied Physiology, 115, 947-957.

Vigouroux, L., \& Quaine, F. (2006). Fingertip force and electromyography of finger flexor muscles during a prolonged intermittent exercise in elite climbers and sedentary individuals. Journal of Sports Sciences, 24, $181-$ 186.

Vigouroux, L., Rossi, J., Foissac, M., Grélot, L., \& Berton, E. (2011). Finger force sharing during an adapted power grip task. Journal of Neuroscience Letters, 504, 290-294.

Watts, P. B. (2004). Physiology of difficult rock climbing. European Journal of Applied Physiology, 91(4), 361-372.

Winter, D. (1990). Biomechanics and motor control of human movement. New-York, NY: Wiley-Interscience.

Youdas, J. W., Amundson, C. L., Cicero, K. S., Hahn, J. J., Harezlak, D. T., \& Hollman, J. H. (2010). Surface electromyographic activation patterns and elbow joint motion during a pull-up, chin-up, or perfect-pullup ${ }^{\mathrm{TM}}$ rotational exercise. Journal of Strength and Conditioning Research., 24, 3404-3414. 